\title{
Temporal load resolution impact on PV/grid system energy flows
}

\author{
Marek Jaszczur ${ }^{1, *}$, Qusay Hassan ${ }^{1,2}$, and Janusz Teneta ${ }^{3}$ \\ ${ }^{1}$ AGH University of Science and Technology, Faculty of Energy and Fuels, Krakow, Poland \\ ${ }^{2}$ University of Diyala, Mechanical Engineering Department, Diyala, Iraq \\ ${ }^{3}$ AGH University of Science and Technology, Faculty of Electrical Engineering, Krakow, Poland
}

\begin{abstract}
In this paper, an investigation of the electrical load temporal resolution on the PV/Grid energy system flows, and self-consumption is done in order to determine the optimum parameters for modelling and simulation. The analysed PV/Grid power systems include a photovoltaic system with the nominal power of $\mathrm{P}_{\max @ \mathrm{STC}}=1.5,2.5,3.5 \mathrm{~kW}$ without storage unit connected to the grid. The results show that the temporal load resolution may have a high impact on energy flows as well as can be a critical issue for the system analysis accuracy even for the single household. It has been found that the load temporal resolution for energy consumption of 1-min yields reliable results, while data resolutions of 5 and 15 min are still sufficient, however, in that case, the daily electrical energy flows and in consequence energy selfconsumption estimation error for selected days may exceed $15 \%$. Acquisition time step longer than 15minutes may increase error above $20 \%$ and from the designer's point of view should not be used. The high and low temporal resolution experimental data of the electricity consumption (load) for a household are available in digital form on the author's website http://home.agh.edu.pl/jaszczur.
\end{abstract}

\section{Introduction}

The Sun provides energy for all parts of the Earth, and this type of energy can be considered as a one of the most promising among renewable energy resources, due to free availability, clean and sustainable [1]. However, many parts of the World are still struggling to meet their demand. The photovoltaic (PV) module is capable of harnessing and converting energy from the Sun directly into most useful electrical energy [2]. At present, the efficiency of PV systems has not achieved the satisfying level, due to influenced by a large number of technical factors (cell efficiency, optical efficiency). PV system performance also depends on a large number of environmental factors as: air temperature, wind speed, air pollution, the angle of incident irradiation, solar radiation spectrum, snow and shadowing, and scientists are still working to gain the performance of the PV systems [3]. In recent years, a large number of countries have shown a growing interest in the installation of solar energy based systems on the roofs of the household/building. Notably, on-grid PV systems received the most attention for overcoming the intermittent nature of renewable sources, the issue of over-scaling and enhancing supply reliability $[4,5]$. Modelling and optimisation of such systems are the key issue and subject to specific constraints that are not only of a technical point of view. From contributors in the energy system, optimisation can see as obtaining the best result of committed resources, including both energy sources and economic factor, under some constraints derived from the number of specific objectives. The electrical energy flows in PV/Grid power systems depends on many system parameters, e.g., system size, system type, solar radiation and load (energy consumption) profile. For analysing renewable energy system connected to the grid, the electrical energy flows from/to the grid have to be investigated. However, all these types of investigation should rely on reliable data for a load of residential electricity consumption. The electrical energy flows in the PV real system depend the on the actual data only, but for the system analysis, it may also depend on the analysis time step and temporal resolution of the input data. Usually, due to technical limitation and storage units, it is not practical to use high temporal resolutions data in the order of seconds for solar radiation or energy consumption, however, for electric digital energy meter, at least one-second sampling rate is used whereas for analogue electrical meter fully continuous sampling rate is implemented. For this reason, it is an important issue to get detailed knowledge about the influence of the temporal load resolution on the energy flow in such systems when analysed.

In the literature, a few studies have been reported modelling PV/grid energy systems with an indirect focus on load temporal resolution. Osawa et al. [6] investigate improving PV self-consumption for charging the vehicle. The simulation was done for the one-year time span, resulting with $3.4 \mathrm{~kW} \mathrm{PV}$ system and the result shows that self-consumption reach up to $79 \%$ with optimised charge/discharge control and utilisation of the electric vehicle battery. For a single-family house with two parents and one child, $10.8 \mathrm{~kW}$ PV system was studied

\footnotetext{
* Corresponding author: jaszczur@agh.edu.pl
} 
by Vrettos et al. [7] resulting in the self-consumption percentage increase around $17 \%$ by using optimising algorithms for batteries charging. In another work Femia and Zamboni [8] show the results of selfconsumption analysis and obtain value of about $16 \%$ without storage and without load management, 31\% without storage and with load management, $33 \%$ with storage and without load management and $48 \%$ with storage and with load management for a flat with two people. Similar work was done by Cagigal et al. [9] for two weeks span and $5.55 \mathrm{~kW}$ PV system with $5.4 \mathrm{kWh}$ battery storage. The results showed that the PV selfconsumption could be improved by around 33\% with storage and without load management, $42 \%$ with storage and with load management. From presented examples and as written by Petrollese and Cocco [10] there are two main effective ways for increased PV self-consumption: the energy storage and the load management. In the literature [11-20] a large number of studies have been done using battery storage for increase self-consumption. In [21-24] management shifting of flexible electric loads in households have been analysed to optimise the utilisation of the PV production. Two methods of consideration provided to enhance self-consumption are described in [25-28]. In a study performed by Denholm \& Margolis [29] authors conclude that by using electrical storage systems and load shifting it is possible to maximise PV energy self-consumption. At present, the PV grid-connected systems offer constructive solutions to improve the grid and services at the same time; the grid network should be designed to respond for this shape by using a modern updated solution such as a storage system using, controlling consumption or adapting generation.

The effects of the PV size on self-consumption on the aggregated consumption of electrical grid have been studied by Calpa et al. [30]. The authors reported that the PV self-consumption could facilitate the overall consumption of the system. On the other hand, direct use of the energy from the PV system can increase the overall consumption volatility of high penetration levels. For the large-scale PV power plant, the self-consumption mechanism has been analysed by Şenol et al. [31]. Authors concluded a need for installing large scale PV plant with high self-consumption and with optimal power capacity by considering technical and economic aspects. In the research done by Castillo-Cagigal et al. [32], the PV self-consumption was evaluated using artificial intelligence techniques. Optimal operating strategies of the PV system analysis have been the subject of extensive research on the PV/Grid systems.

Available in the literature studies use different modelling approaches and strategies however in most of the studies a single arbitrarily selected input temporal resolution or simulation time step are used for analysis. In other words energy consumption (load) and solar radiation data, temporal resolution was used without any justification. It is clear that obtaining temporal resolution data in the order of seconds for solar radiation and load is complicated and maybe unpractical and for this reason, 15 or $60 \mathrm{~min}$ data are usually used. However, input data temporal resolution and time step may generate significant analysis errors in any analysis of this type. For this reason, this work aims to determine the optimum temporal resolution for electrical load and solar radiation measurement.

\section{Methodology}

In order to determine the impact of the electrical load and solar radiation temporal resolution on the energy flows as well as PV system self-consumption, detailed system analysis were performed for a single household and three different PV systems with nominal power equal to $1.5,2.5$ and $3.5 \mathrm{~kW}_{\mathrm{p}}$. The PV system is equipped with a single-phase inverter. Polycrystalline silicon PV panels with 13\% efficiency at STC condition we used. The system under consideration has the following orientation: tilted angle $\beta=35^{\circ}$ and azimuth angle $\gamma=20^{\circ}$ (south), and the system has been located in Kraków city (50.066092N, 19.921835E), Poland.

\subsection{Load demand}

The experimental measurements of the electrical AC load for a household in Krakow, Poland was performed using energy meter (OWI 2.8:1096) with transmitter (CM180) for the period 01.01.2017-31.12.2017. The considered household is flat with area of $70 \mathrm{~m}^{2}$, has three rooms and is occupied by two adults. The heating system, hot water, and the cooker are supplied with natural gas. The yearly electrical energy consumption was $1.815 \mathrm{MWh}$ in 2017.
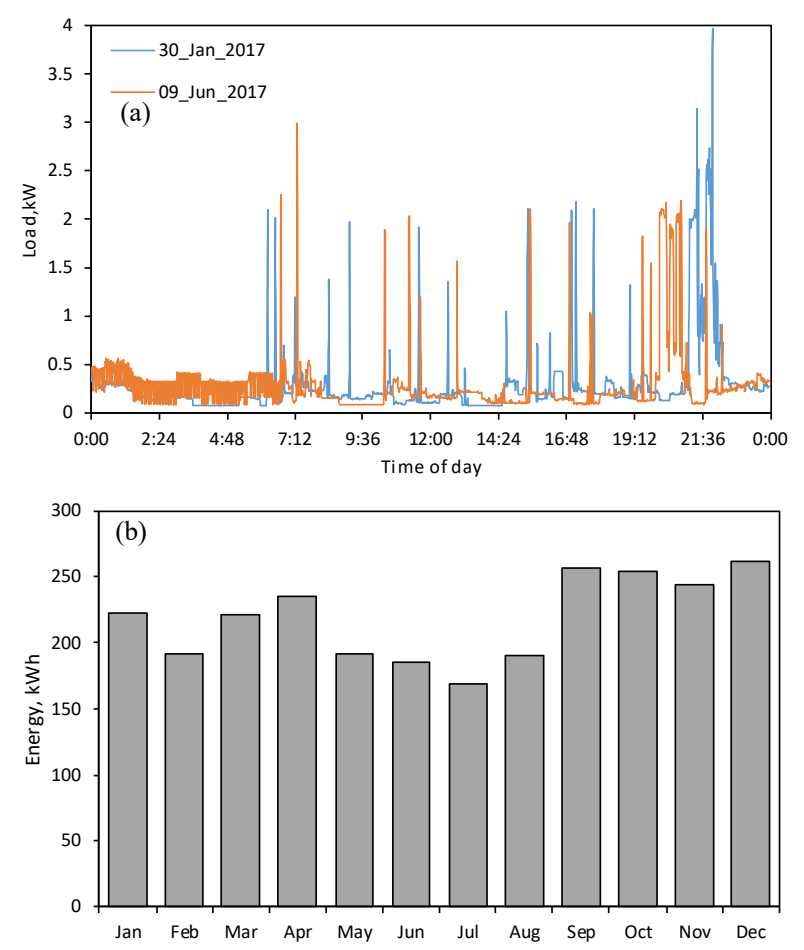

Fig. 1. The instantaneous daily load distribution (a) and monthly averaged electrical load (b) for 2017.

The measurement device data acquisition time was at least 1-minute (typically 10-60 sec) and depends on the electrical power fluctuation. 
However, for the present study, an original nonuniform time step measurement has been re-sampled by means averaging procedure to the 60 seconds temporal resolution. Base on default 60 seconds resolution, four different temporal resolutions for the load has been created equal to: $5,15,30$ and 60 minutes. The daily load distribution and monthly average energy consumption from experimental measurements are presented in Figure 1(a) and 1(b) respectively.

\subsection{Solar irradiation}

In order to performed on gridPV system analysis, require the global (GHI) and diffused components (DHI) of solar radiation were measured by pyranometers (Kipp \& Zonen CM 21). Measurements were obtained every second, then averaged over $5 \mathrm{~min}$, and recorded by a Combilog 1200 datalogger (Theodor Friedrichs). These measurements have been recorded over the entire year of 2017. The daily distribution and monthly averaged solar radiation are shown in Figure 2(a)-(b) respectively. Results show that the monthly averaged solar radiation and daily solar radiation distribution vary significantly by the month.
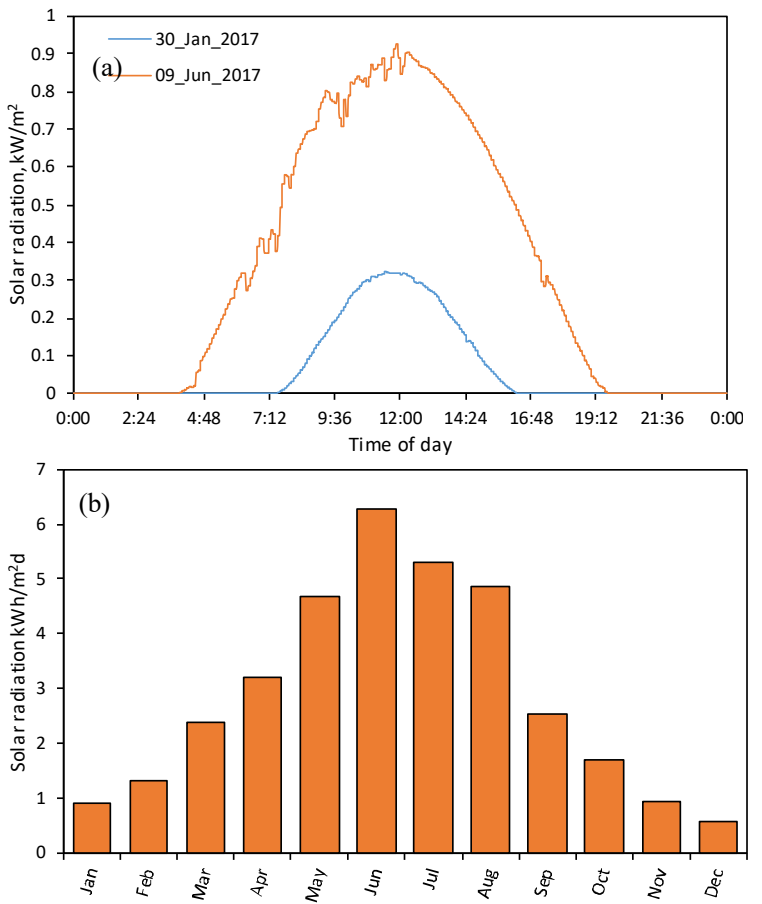

Fig. 2. Daily (a) and monthly averaged (b) total solar radiation distribution.

\section{Mathematical modelling}

\subsection{Power of PV}

The PV panel electrical power depends on the incident solar radiation $G_{T}$ (global component) and can be calculated according to the following formula [3]:

$$
P_{P V}=C_{P V} D_{P V}\left[1+\alpha_{P}\left(T_{c}-T_{c, S T C}\right)\right]\left(\frac{G_{T}}{G_{T, S T C}}\right)
$$

where $P_{P V}$ is the photovoltaic panel generated power, $C_{P V}$ is the PV panel rated capacity, $D_{P V}$ is the PV derating factor, $\alpha_{P}$ is the PV thermal coefficient of power, $T_{c}$ is the PV module temperature, $G_{T, S T C}$ and $T_{c, S T C}$ are the solar irradiation and panel temperature at STC conditions. In this work the effect of the module temperature on the PV power not taken into account.

\subsection{Load balance equation}

The instantaneous load balance equation ensures that the electricity demand of the household is satisfied at all times from the photovoltaic system or from the grid system, as follows:

$$
P_{\text {Laod }, t}=P_{\text {From grid }, t}+P_{P V, t}
$$

where $P_{\text {Load, }, t}$ is the instantaneous electrical load demand, $P_{\text {From grid, } t}$ instantaneous power taken from the grid and $P_{P V, t}$ instantaneous PV generated power. The load balance equation, describes the power flows between the system components, and can be calculated with the following constraints:

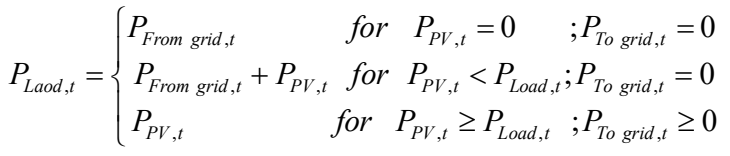

\subsection{PV self-consumption}

The outline of the power profiles of on-site PV power generation and consumption can divide into 3 components: the electricity generation, the total net electricity demand, and the absolute self-consumption [33]. The self-consumption is the electricity generated by the photovoltaic system that is consumed directly by the household. Self-consumption (SC) and self-sufficiency (SS) are defined as follows:

$$
\begin{aligned}
& S C=E_{P V, \text { consumed }} / E_{P V, \text { generated }} \\
& S S=E_{P V, \text { consumed }} / E_{\text {total }}
\end{aligned}
$$

where $E_{P V}$, consumed is the $\mathrm{PV}$ energy consumed directly by the household, $E_{P V}$, generated photovoltaic system energy generation and $E_{\text {total }}$ household energy demand. The analysed here on-grid PV system was calculated with time step $\Delta \mathrm{t}=1 \mathrm{~min}$ as follows:

$$
\text { Energy }=\sum_{t=1}^{t=n} E_{\text {From grid }, t}-\sum_{t=1}^{t=n} E_{\text {To grid }, t}
$$

where $E_{\text {From grid, }} E_{\text {To grid }}$ and $n$ are the energy from the grid, energy fed to the grid, and $n$ is equal to the number time steps respectively.

\section{Results}

All performed analysis is based on experimental measurement for load and solar irradiation. Figures 3(a)3(d) and Figures 4(a)-3(d) shows the load and the PV system instantaneous power for the selected sunny and cloudy days respectively and the load input data temporal resolution equal to $1,15,30$ and $60 \mathrm{~min}$ respectively. For the solar irradiation fixed temporal resolution equal to 5 minutes was considered. The common area under the curve of the solar radiation and load represents self-consumption. One may easy inferred from results the impact of the different load temporal resolution on the energy-self consumption (common 
area). However, one should notice that changes in selfconsumption are apparent created by the input data resolution and the real system self-consumption is fixed.
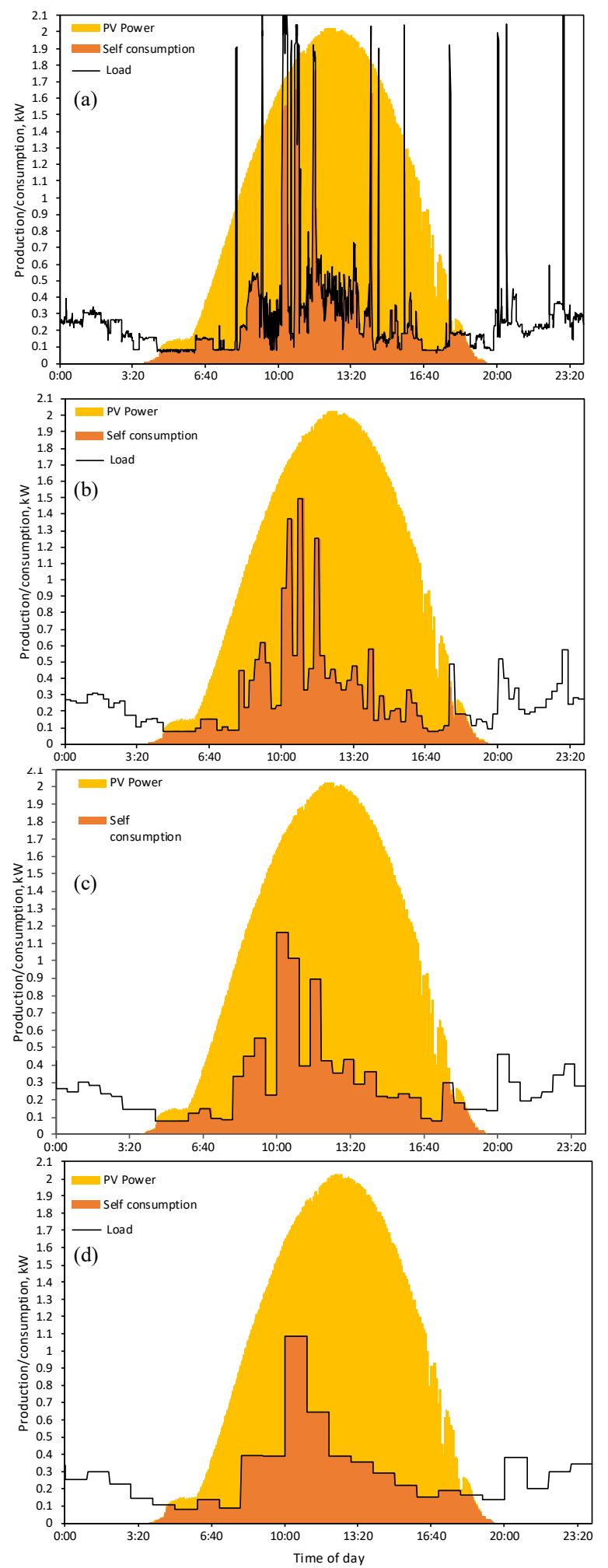

Fig. 3. Load, PV power and self-consumption for $2.5 \mathrm{~kW}_{\mathrm{p}} \mathrm{PV}$ system for a sunny day (03.06.2017) and load temporal resolution: $1 \mathrm{~min}(\mathrm{a}), 15 \mathrm{~min}(\mathrm{~b}), 30 \mathrm{~min}(\mathrm{c}), 60 \mathrm{~min}(\mathrm{~d})$.

The total energy consumption for the selected sunny day is $6.98 \mathrm{kWh}$, while the energy supplied by the 2.5 $\mathrm{kW}_{\mathrm{p}} \mathrm{PV}$ system is $16.3 \mathrm{kWh}$. The real daily energy consumption is temporal resolution independent and constant by definition; however, the energy distribution due to averaging may vary significantly for different resolutions. Particularly, the maximum power peaks become much lower and wider.
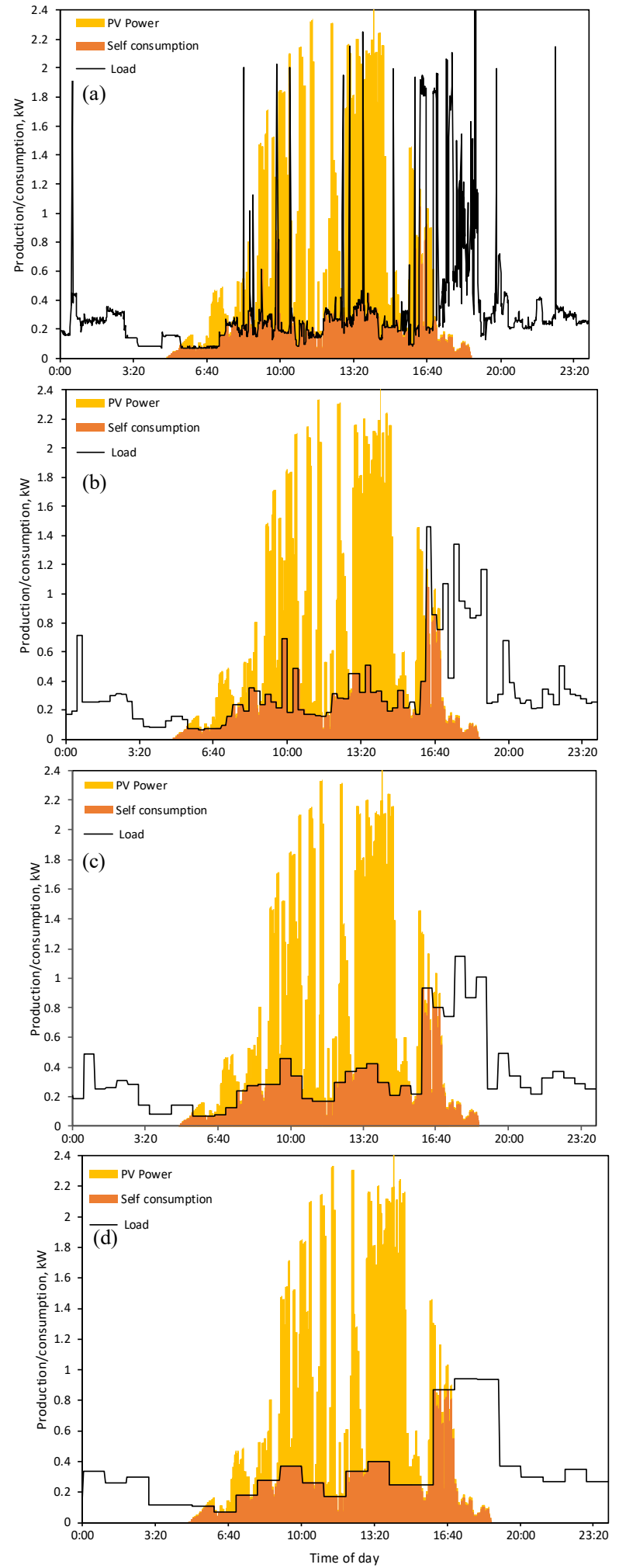

Fig. 4. Load, PV power and self-consumption for $2.5 \mathrm{~kW}_{\mathrm{p}} \mathrm{PV}$ system for a partly cloudy day (05.06.2017) and load temporal resolution: $1 \mathrm{~min}(\mathrm{a}), 15 \mathrm{~min}(\mathrm{~b}), 30 \mathrm{~min}(\mathrm{c}), 60 \mathrm{~min}(\mathrm{~d})$.

The daily energy consumption for the selected cloudy day is $8.08 \mathrm{kWh}$, while the total energy generated by the PV system is $10.47 \mathrm{kWh}$.

The energy flows obtained from the grid, fed to the grid and PV self-consumed for different load temporal 
resolutions for presented sunny and cloudy days are shown in Tables 1 and 2 respectively.

Table 1. Daily energy from/to the grid and self-consumption for $2.5 \mathrm{~kW}_{\mathrm{p}}$ PV system on presented sunny day.

\begin{tabular}{|c|c|c|c|}
\hline $\begin{array}{c}\text { Resolution } \\
\text { of the load } \\
\text { (min) }\end{array}$ & $\begin{array}{c}\text { Energy taken } \\
\text { from the grid } \\
\text { (kWh) }\end{array}$ & $\begin{array}{c}\text { Energy fed to } \\
\text { the grid } \\
\text { (kWh) }\end{array}$ & $\begin{array}{c}\text { PV self- } \\
\text { consumption } \\
\text { (kWh) }\end{array}$ \\
\hline 1 & 2.75 & 10.47 & 4.22 \\
\hline 5 & 2.61 & 10.33 & 4.37 \\
\hline 15 & 2.42 & 10.14 & 4.55 \\
\hline 30 & 2.38 & 10.1 & 4.59 \\
\hline 60 & 2.36 & 10.08 & 4.61 \\
\hline
\end{tabular}

Table 2. Daily energy from/to the grid and self-consumption for $2.5 \mathrm{~kW}_{\mathrm{p}}$ PV system on presented cloudy day.

\begin{tabular}{|c|c|c|c|}
\hline $\begin{array}{c}\text { Resolution } \\
\text { of the load } \\
\text { (min) }\end{array}$ & $\begin{array}{c}\text { Energy taken } \\
\text { from the grid } \\
\text { (kWh) }\end{array}$ & $\begin{array}{c}\text { Energy fed } \\
\text { to the grid } \\
\text { (kWh) }\end{array}$ & $\begin{array}{c}\text { PV self- } \\
\text { consumption } \\
\text { (kWh) }\end{array}$ \\
\hline 1 & 5.26 & 6.58 & 2.82 \\
\hline 5 & 5.08 & 6.4 & 3.00 \\
\hline 15 & 4.83 & 6.15 & 3.26 \\
\hline 30 & 4.71 & 6.03 & 3.37 \\
\hline 60 & 4.69 & 6.01 & 3.39 \\
\hline
\end{tabular}

The different load temporal resolutions affect the apparent energy flow in the PV system. The errors related to the apparent flows can be calculated in reference to the high-resolution results (1 minute) using $\mathrm{SC}$ at two different resolutions.

Absolute errors $=\mathrm{SC}_{2}$ resolution- $\mathrm{SC}_{1 \text { resolution }}$

Relative errors $=\mathrm{SC}_{2}$ resolution- $\mathrm{SC}_{1 \text { resolution }} / \mathrm{SC}_{1}$ resolution

The absolute and relative errors for PV selfconsumption caused by the different load temporal resolutions for presented sunny day and $2.5 \mathrm{~kW}_{\mathrm{p}} \mathrm{PV}$ system are shown in Figure 5(a) and (b) respectively.
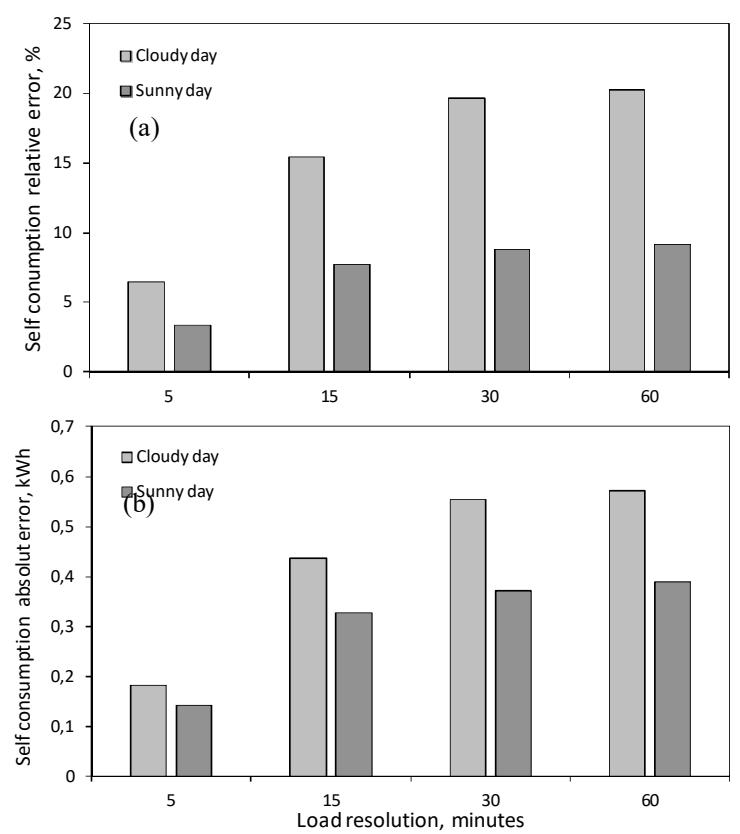

Fig. 5. The self-consumption absolute (a) and relative errors (b) vs. temporal load resolution for cloudy and sunny days.

The yearly energy flows, from/to grid and selfconsumption at different load resolution for three different PV systems 1.5, 2.5 and $5.3 \mathrm{~kW}_{\mathrm{p}}$ and for the year 2017 are shown in Tables 3, 4 and 5 respectively.
Table 3. Energy from/to the grid and self-consumption for $1.5 \mathrm{~kW}_{\mathrm{p}}$ PV system (whole year 2017).

\begin{tabular}{|c|c|c|c|}
\hline $\begin{array}{c}\text { Resolution } \\
\text { of the load } \\
\text { (min) }\end{array}$ & $\begin{array}{c}\text { Energy taken } \\
\text { from the grid } \\
\text { (kWh) }\end{array}$ & $\begin{array}{c}\text { Energy fed } \\
\text { to the grid } \\
\text { (kWh) }\end{array}$ & $\begin{array}{c}\text { PV self- } \\
\text { consumption } \\
\text { (kWh) }\end{array}$ \\
\hline 1 & 2091.80 & 796.03 & 528.26 \\
\hline 5 & 2069.19 & 772.87 & 551.43 \\
\hline 15 & 2048.42 & 752.02 & 572.28 \\
\hline 30 & 2033.00 & 736.60 & 587.70 \\
\hline 60 & 2016.73 & 720.33 & 603.97 \\
\hline
\end{tabular}

Table 4. Energy from/to the grid and self-consumption for $2.5 \mathrm{~kW}_{\mathrm{p}}$ PV system (whole year 2017).

\begin{tabular}{|c|c|c|c|}
\hline $\begin{array}{c}\text { Resolution } \\
\text { of the load } \\
\text { (min) }\end{array}$ & $\begin{array}{c}\text { Energy taken } \\
\text { from the grid } \\
\text { (kWh) }\end{array}$ & $\begin{array}{c}\text { Energy fed } \\
\text { to the grid } \\
\text { (kWh) }\end{array}$ & $\begin{array}{c}\text { PV self- } \\
\text { consumption } \\
\text { (kWh) }\end{array}$ \\
\hline 1 & 1977.96 & 1563.61 & 642.10 \\
\hline 5 & 1951.32 & 1536.41 & 669.30 \\
\hline 15 & 1926.92 & 1511.93 & 693.78 \\
\hline 30 & 1908.52 & 1493.53 & 712.18 \\
\hline 60 & 1893.42 & 1478.43 & 727.28 \\
\hline
\end{tabular}

Table 5. Energy from/to the grid and self-consumption for $3.5 \mathrm{~kW}_{\mathrm{p}}$ PV system (whole year 2017).

\begin{tabular}{|c|c|c|c|}
\hline $\begin{array}{c}\text { Resolution } \\
\text { of the load } \\
\text { (min) }\end{array}$ & $\begin{array}{c}\text { Energy taken } \\
\text { from the grid } \\
\text { (kWh) }\end{array}$ & $\begin{array}{c}\text { Energy fed } \\
\text { to the grid } \\
\text { (kWh) }\end{array}$ & $\begin{array}{c}\text { PV self- } \\
\text { consumption } \\
\text { (kWh) }\end{array}$ \\
\hline 1 & 1902.86 & 2372.84 & 717.19 \\
\hline 5 & 1876.98 & 2346.40 & 743.65 \\
\hline 15 & 1852.14 & 2321.49 & 768.55 \\
\hline 30 & 1835.20 & 2304.55 & 785.49 \\
\hline 60 & 1821.69 & 2291.03 & 799.01 \\
\hline
\end{tabular}

The absolute and relative errors for on-grid PV system self-consumption due to different load temporal resolutions for three PV system sizes are shown in Figure 6(a) and Figure 6(b) respectively.

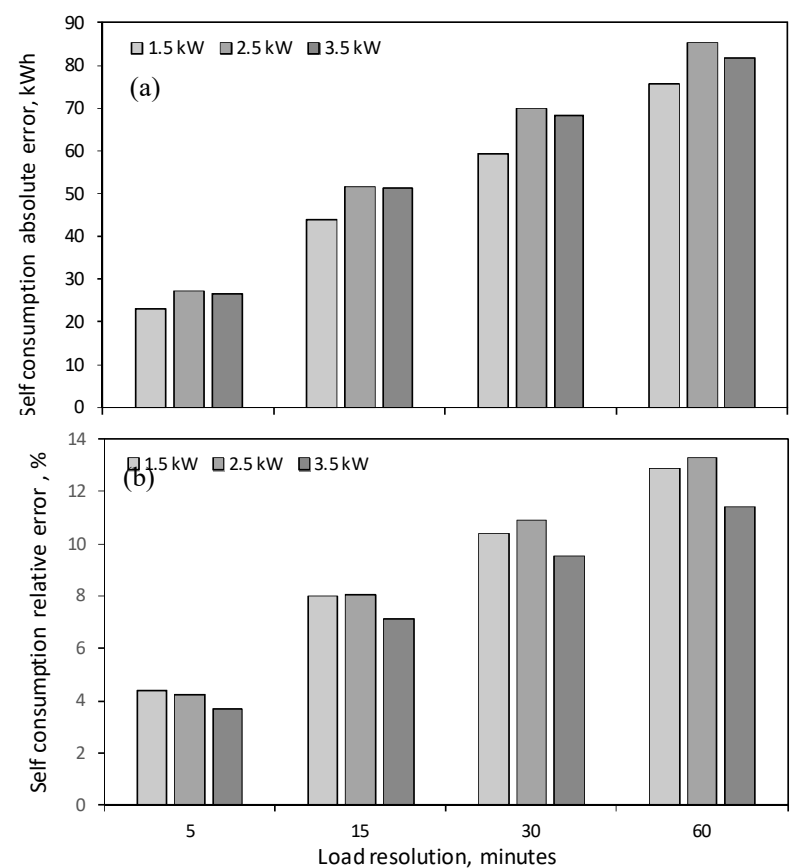

Fig. 6. The yearly self-consumption absolute (a) and relative errors (b) due to load temporal resolution.

\section{Conclusions}


The study investigated electrical load temporal resolution, and the photovoltaic system size $(1.5,2.5$ and $3.5 \mathrm{~kW}_{\mathrm{p}}$ ) effect on the on-grid PV system energy flows. The results showed that power also flows might differ significantly if the load temporal resolution is too high. The relative and absolute errors of the analysis increase with increasing load temporal resolution. The energy self-consumption underestimation for presented cloudy day for the $2.5 \mathrm{~kW}_{\mathrm{p}} \mathrm{PV}$ and the resolutions $5,15,30$ and 60 minutes is $0.18,0.44,0.55,0.57 \mathrm{kWh}$ while for the presented sunny day is $0.15,0.32,0.37,0.39 \mathrm{kWh}$ (for sunny day) respectively. The relative error recorded is $6.4,15.6,19.5,20.2 \%$ for the cloudy day, and $3.6,7.8$, $8.8,9.2 \%$ for sunny day respectively.

The relative yearly error for self-consumption estimation due to load temporal resolution $60 \mathrm{~min}$ depends on system size and for the $1.5 \mathrm{~kW}_{\mathrm{p}} \mathrm{PV}$ is $14.33 \%$ while for the 2.5 , and $3.5 \mathrm{~kW}_{\mathrm{p}} \mathrm{PV}$ are $13.3 \%$ and $11.4 \%$ respectively. It has been found that the load temporal resolution of 1 -min yields reliable results, while data lower resolutions of 5 and $15 \mathrm{~min}$ are still sufficient, however, lower than 15-minutes resolution may increase daily error above $20 \%$ and should not be used by system designers, computer software and system analysis tools.

The high and low temporal resolution experimental data of the electricity consumption (load) for a household are available in digital form on the author's website http://home.agh.edu.pl/jaszczur.

\section{Acknowledgements}

The present work supported by the Polish Ministry of Science (Grant AGH 15.11.210.436 and 11.11.210.312).

\section{References}

1. H. Gujba, Y. Mulugetta, A. Azapagic, Energy Policy 39, 968-980 (2011)

2. S. Dubey, J.N. Sarvaiya, B. Seshadri, Energy Procedia 33, 311-321 (2013)

3. Q. Hassan, M. Jaszczur, E. Przenzak, E3S Web of Conferences 14, 01028, (2017)

4. A. Franco, M. Shaker, D. Kalubi, S. Hostettler, Sustainable Energy Tech. and Assessments (2017)

5. I.P. Panapakidis, D.N. Sarafianos, M.C. Alexiadis, Rene. and Sust. Ene. Rev. 16, 551-563 (2012)

6. M. Osawa, K. Yoshimi, D. Yamashita, R. Yokoyama, T. Masuda, H. Kondou, T. Hirota, (ISGT Asia, IEEE, 1-6, 2012)

7. E. Vrettos, A. Witzig, R. Kurmann, S. Koch, G. Andersson, (EU PVSEC, 2013)

8. N. Femia, D. Toledo, W. Zamboni, (IECON 39th IEEE , 6800-6805, 2013)

9. M. Castillo, E. Matallanas, D. Masa, E. Caamaño, A. Gutiérrez, F. Monasterio, J. Jiménez, (GeDELOS-PV system, 2010)

10. M. Petrollese, G. Cau, D. Cocco, Applied Energy, 212, 746-758 (2018)
11. J. Widén, E. Wäckelgård, D. Lund, Solar Energy 83, 1953-1966 (2009)

12. J. Li, M.A. Danzer, Journal of Power Sources 258, 365-373 (2014)

13. Q. Hassan, M. Jaszczur, M. Mohamed, K. Styszko, K. Szramowiat, J. Gołaś, E3S Web of Conferences 10, 00093 (2016)

14. R. Kanamori, T. Ito, N. Mizutani, (SOCA, IEEE, 15, 2011)

15. G. Mulder, D. Six, B. Claessens, T. Broes, N. Omar, J. Van Mierlo, Applied Energy 111, 1126-1135 (2013)

16. B. Ceran, Q. Hassan, M. Jaszczur, K. Sroka, E3S Web of Conferences 14, 01020 (2017)

17. A. Bayod-Rujula, E. Haro-Larrode, A. MartinezGracia, Solar Energy 98, 582-591(2013)

18. L. Nge, M. Midtgard, L. Norum, (PowerTech, IEEE Trondheim, 1-6, 2011)

19. B. Song, Y. Jung, H. Ji, C. Choi, W. Lee, Y. Won, (Asia, (ICPE \& ECCE), IEEE, 2625-2630, 2011)

20. E. Waffenschmidt, Energy Procedia 46, 88-97 (2014)

21. J. Munkhammar, J. Widén, WREF and CRES, 18581865 (2012)

22. M. Chaabene, M.B. Ammar, A. Elhajjaji, Applied Energy 84, 992-1001 (2007)

23. Q. Hassan, M. Jaszczur, E. Przenzak, J. Abdulateef, (Contemporary Problems of Power Engineering and Environmental Protection 33, 2016)

24. Y. Zong, L. Mihet-Popa, D. Kullmann, A. Thavlov, O. Gehrke, W. Bindner, (ISGT, IEEE, 1-8, 2012)

25. E. Matallanas, M. Castillo, A. Gutiérrez, F. Monasterio, E. Caamaño, D. Masa, J. Jiménez, Applied Energy 91, 90-97 (2012)

26. C. Clastres, T.H. Pham, F. Wurtz, S. Bacha, Energy 35, 55-64 (2010)

27. A. Barbato, A. Capone, G. Carello, M. Delfanti, M. Merlo, A. Zaminga, (SmartGridComm, IEEE, 345350, 2011)

28. M. Jaszczur, Q. Hassan, J. Teneta, J. Abdulateef, Journal of Thermal Science, (2018)

29. P. Denholm, M. Margolis, Energy Policy 35, 44244433 (2007)

30. M. Calpa, M. Castillo-Cagigal, E. Matallanas, E. Caamaño-Martín, A. Gutiérrez, Procedia Computer Science 83, 816-823 (2016)

31. M. Şenol, S. Abbasoğlu, O. Kükrer, A.A. Babatunde, Solar Energy 132, 518-537 (2016)

32. M. Castillo-Cagigal, E. Maallanas, F. MonasterioHuelin, E.C. Martín, A. Gutiérrez, IEEE Transactions on Industrial Informatics 12, 941-951 (2016)

33. R. Luthander, J. Widén, D. Nilsson, J. Palm, Applied Energy 142, 80-94 (2015) 